\title{
What does UN environment's GEO-6 mean for INEA?
}

\author{
Joyeeta Gupta ${ }^{1}$
}

Published online: 8 March 2019

(c) Springer Nature B.V. 2019

\section{The mission of INEA}

\subsection{International environmental agreements}

Politics, Law and Economics was born in 2001, in response to the perceived need for analysis that examines the challenges in international environmental agreements-did these agreements achieve their environmental goals? What were the politics that affected such agreements? Was the progressive development of international law able to cope with the multiple challenges that environmental problems posed globally? How did economic perspectives pervade and influence the design of global environmental treaties? Nineteen years later, a key question we should be asking is, who reads and cites our work? Does it have the necessary impact on the global scientific community? Does it have an impact on the policy community? And if the answers to both questions are-it has marginal impacthow can we increase the impact of the journal?

With a view to understanding these broader questions, I looked at the 2019 Global Environment Outlook-6 (GEO-6): Healthy Planet, Healthy People, just produced by United Nations Environment and in press with Cambridge University Press. I am in an ideal place to do this as I am co-chair of GEO-6. I looked at whether our papers are being cited by GEO-6. A total of six papers were cited in GEO-6, which one could argue is disappointing, as more than 2880 papers are cited. But on closer examination, this may have also been because GEO-6 did not really evaluate the international environmental agreements and lessons learnt, but focused more extensively on lessons that can be learnt at national level from national policy processes. GEO-5 covered international agreements and financial and other related issues and maybe it was a logical progression for GEO-6 to focus more on lessons learnt from domestic and regional experiences. The other reason may also be that journals like INEA do not always take the time to draw out lessons from the collective scientific knowledge within the journal. This may be a good reason to revisit the collective knowledge in INEA in its twentieth year-2020.

Let us then look at what can we learn from the current assessment of the science, policy and outlooks in UN Environment's GEO to draw lessons on the kinds of issues INEA should be concerned with in the future. We could also look at lessons that can be learnt from the science-policy encounter embodied in the GEO process.

Joyeeta Gupta

J.gupta@uva.nl

1 University of Amsterdam, Amsterdam, The Netherlands 


\section{UN environment's global environment outlook-6: substantive implications}

Coming in the wake of Agenda 2030 and the sustainable development goals (SDGs), the Paris Agreement on Climate Change, and the most recent IPCC report on $1.5{ }^{\circ} \mathrm{C}$, GEO-6 is an exciting report, although as co-chair, I am scarcely an impartial person. Technically, United Nations Environment only has the mandate to engage with the environmental component of the Sustainable Development Goals. However, as Agenda 2030 emphasizes that all Goals are interrelated and indivisible - the environmental component cannot be compartmentalized and achieved, but in designing instruments to achieve it- the social and economic components must also be accounted for. Furthermore, the SDGs require that no one is left behind, which is an explicit injunction to take the environmental impacts on the poorest into account and to examine how responsible they are for environmental problems. Thus, Agenda 2030 has changed the context within which UN Environment can prepare its flagship report.

The report is exciting because it links all available knowledge on the different system components (air, land, water, oceans and biodiversity) to make the case that the interconnections between these systems lead to cascading impacts through the entire system. It is exciting because it links these impacts with the way we are defining growth in our linear systems of using resources and discarding wastes; and because it explicitly links with the growing impacts on human health and well-being.

The report presents population dynamics-growth and aging, urbanization, economic growth, technology and climate change as key drivers of environmental problems. Addressing each requires tailor-made solutions such as investing in gender equality, inequality and infant health to account for population dynamics; reducing the environmental footprint in urban settings through better planning and infrastructure; focusing on development and a circular economy as opposed to the linear growth model; adopting the precautionary approach to new technologies to enhance opportunities for increased efficiency and effectiveness without creating new risks; and mitigating climate change urgently. It shows how the different system components - air, biodiversity, land, oceans and water-are being affected by human behavior and how this in turn affects human health. In doing so, it builds on a series of publications by the World Health Organization and the Lancet.

The policy section focuses less on the dynamics of international treaties than it does on the dynamics of national policies - the range of policy instruments and whether and how these can be designed to enhance their effectiveness, and what kinds of policy mixes may be effective. It points to the lack of systematic data collection on why and under what circumstances each of these instruments can contribute to goal achievement. It concludes that policies should be designed for effectiveness, with clear baselines, with an understanding of the costs and benefits, through ensuring policy coherence and synergy, and should be revised based on independent evaluation studies. It recommends the inclusion of key actors, the use of policy-sensitive indicators and supports research on policy effectiveness. What is curious is that despite the heavy investment in equity and gender-related issues in the report, the lessons learnt from the analysis did not say anything specific-except the need to include stakeholders in policy design and take social issues into account.

The Outlooks section looks at the future and assesses the potential for achieving the different Sustainable Development Goals and recommends a diverse set of pathways that are consistent with achieving the environmental goals of the global community. It emphasizes the need to take distributive justice into account in addressing environmental issues. 
Transformative policies require a vision, innovation, phasing out of unsustainable practices, policy experimentation and engaging and mobilizing enabling actors and stakeholders. The above summary does not of course do justice to the rich data that the report presents in making its case that our environment is rapidly deteriorating with consequent impacts on human health; and that investing in human health is synergistic to investing in the environment. But clearly, the scholarship on the politics of decision-making is conspicuous by its absence. This, however, does not mean that there was no engagement with the politics in the process of writing the GEO-6.

\section{UN environment's global environment outlook-6: process-related issues}

\subsection{Issues raised by the high-level panel}

GEO-6 had a complicated process. With a mandate from governments and a strict governing process, there is limited freedom for authors to write their own narrative. The process is closely monitored by a High-Level Intergovernmental and Stakeholder Advisory Group (HLG). This Group consists of both governmental and non-governmental stakeholders. It consists of people with strongly held ideas about what can and cannot be included. This leads, for example, to issues that must be excluded or made subject to multi-interpretable language. It also leads to issues that must be included. There is a continuous negotiation regarding the line between what cannot and cannot be included.

Three key issues raised questions include: (a) questioning growth and discussing the potential for degrowth; (b) is the transition needed gradual, transformative and/or disruptive; and (c) is equity central to environmental challenges?

Growth is the key indicator, that all countries seem to be aiming for. Growth is expected to address all other challenges - by raising the resources needed to address environmental issues, create jobs as well as address inequality. The need to question whether growth is compatible with environmental sustainability, whether growth as expressed by GDP is a good indicator, whether growth data is good enough, whether growth can be compatible with growing inequality and reduced resources for investing in public goods, and whether there are limits to growth as currently defined (a la the Club of Rome) is problematic for most governments worldwide. Degrowth may be a peripheral left-wing idea-scholarship on it has apparently no place in a report that serves national governments.

And yet, the authors of GEO- 6 appear to have found a way around this dilemma. They have argued that instead of thinking of growth, it is better to think about development and well-being; instead of thinking about profits, it is better to think of lost income, lost wealth, lost health and health care costs; and they have shown that growth when accompanied by inequality, as it is presently doing, can lead to a focus on excessive private consumption on the one hand and on the other hand reduced resources for the state to invest in public goods. However, it does not go as far as to test the hypothesis that the reduced resources for public goods lead to public-private partnerships-that may not always benefit the environment or the poor.

Another early debate was whether development trajectories in the future are likely to be evolutionary or disruptive. Disruptive trajectories were discarded-that was not constructive thinking that could enable societies to tackle the big environmental challenges ahead. 
Transformation along existing pathways that accelerate dematerialization, decarbonization and detoxification was seen as more digestible by state actors.

And yet, anyone reading GEO-6 closely will realize that the growing systemic problems link the different system components together. Furthermore, they will see the cascading impacts of climate change on other system components (land, water, oceans and biodiversity) - which is not only seen as a driver of current problems, but as a cross-cutting issue and also as a key challenge of itself - is such that if climate change is not urgently tackled, most SDGs will not be achieved, to say nothing of the growing damage to national GDP and the displacement and loss of lives and livelihoods of people in different parts of the world. The Outlooks section makes figures showing the kinds of changes society needs and it is clear that the trend drawn is not a linear curve but requires a major shift-which is the 'figurative' way of talking about disruption.

Finally, the issue of equity: Are social issues the mandate of UNDP and other UN agencies or are these issues central to environmental policy? Although there was much debate and resistance, the adoption of the SDGs which requires achieving social goals and reducing inequality and meeting the needs of the furthest behind first began to penetrate the discussions gradually. Before long it was more than evident that questions of equity are central to questions of environmental problems and most of the authors were engaging with these issues, at least within the national context. While the focus on the role of science went so far as to discuss the role of the knowledge of indigenous peoples and local communities, in addition to remote sensing and big data, and although the data and knowledge chapters raise questions regarding whose knowledge counts and what sorts of knowledge are financed, and calls for disaggregated data to enable better decision-making, they did not actually explore the politics of knowledge underlying environmental decision-making. However, even though equity issues may not have been central through the report-the report explicitly talks about leaving no one behind, mentions environmental justice four times, and discusses equity about 125 times in the report. In the process, it had the support of some members of the High-Level Group who required that issues related to gender and equity were included.

\subsection{The line-by-line acceptance of the summary for policy makers}

A good litmus test of the policy relevance of a Summary is when policymakers protest. In January 2019, representatives of more than 100 states gathered to accept the Summary for Policy Makers. During the four-day-long discussions, a number of issues emerged-some representing under-covered issues and others key North-South or transatlantic debates. The Palestinian representative made clear that we had overlooked the environmental and health impacts of behavior that affects occupied territories. The Nepalese representative showed that our coverage of the vulnerabilities of mountain regions was inadequate. The Samoan delegate demonstrated that the Summary for Policy Makers may be too long and complicated for small-island states whose very existence is at stake from the impacts of climate change through often no fault of their own. The Indian and Afghanistani delegations successfully objected to a map that they saw as inadequately representing the data that is relevant for their region.

North-South issues were evident in discussions regarding whether agriculture is unsustainable or only unsustainable agriculture is problematic. Many Southern governments felt that demonizing agriculture which provides a vital service to humans is uncalled for, and that the problem was unsustainable agriculture. The scholars argued that large scale 
agriculture is problematic because of the huge impacts on water, land and the atmosphere, to say nothing about the fact that current agricultural systems are the biggest cause of damage to global biodiversity. Another controversial issue was meat consumption: the Summary urged a change in consumption patterns toward less meat consumption. However, this was objected to by the big meat exporting countries as it could have a significant impact on their economies and also by other countries where poorer people and nomadic communities are dependent on meat for their survival. The compromise was found in 'healthy diets' without specifying the nature of healthy diets. A third debate centered around the use of the term 'governance,' objected to vehemently by Argentina. Further inquiry revealed that this relatively innocent term is seen as a challenge to national sovereignty. A fourth debate was around corruption-developing countries would have preferred to see 'inefficiencies,' the industrialized countries preferred 'corruption,' the compromise was to keep 'corruption' although to be honest the underlying report often uses the term corruption but does not cover explicit research on corruption. Transatlantic debates were about whether nanotechnology has negative environmental impacts and how far we should go in interpreting the precautionary approach. Such debates may have been relatively low-key as the US officials were representing a government under 'shut-down.'

\section{Implications for INEA}

GEO-6 raises a number of research questions which include:

- How can one design individual environmental policy instruments to ensure policy effectiveness?

- How can one design environmental policy instruments that are coherent across different system components?

- How can one design equitable, efficient and effective environmental policy mixes?

- Will environmental policies be effective and sustainable if they ignore equity issues?

- Under what circumstances can gender-sensitive policy enhance the effectiveness of environmental policy?

- How should the precautionary principle be interpreted in environmental policy instruments?

- How can one mainstream environmental policy in development design, in agricultural and industrial policy?

- How do legal, economic and political issues affect policy design and their effectiveness? and

- How does the framing of issues affect policy design and effectiveness?

While many of the above questions may be less sensitive in a comparative domestic policy research and political setting, they can become politically contentious at global level. My experiences in the chapter on international cooperation within 15 years of work for the Intergovernmental Panel on Climate Change show that issues of global politics and international environmental justice are often not defined as 'research' and the structure of chapters are focused on the design of instruments for environmental effectiveness rather than on the politics of international decision-making. This is awkward-as the latter is not just politics, it is actively researched in journals such as INEA, and perhaps somewhere in our research there is not just a description of the challenges, but solutions to the problem. 
This brings me to the current issue of INEA. It addresses issues regarding framing: does the framing of climate geoengineering as a way to address climate change marginalize the positions of and impacts on developing countries as Frank Biermann argues. Azusa Uji examines the new Minamata Convention on Mercury and shows how the design of this Convention has learnt from past experiences of designing such Conventions, i.e., it points to the learning embodied in the outputs of existing treaties. Carmen Rodríguez Fernández-Blanco, Sarah L. Burnsa, and Lukas Giessena look at the forest complex to argue that this area is governed by a number of legally binding and non-legally binding governance instruments-which tend to be coherent and synergistic when the issues being discussed are written in vague and multi-interpretable language; but that when the text becomes more detailed, there are major contradictions between the regimes that deal with forests. Tobias Arnoldussen looks at how leaders and laggards within the EU influence air policy and how this changes over time. Karen Holm Olsen and Fatemeh Bakhtiari look at the role sustainability labeling can play in promoting climate mitigation actions relevant to Article 6 of the Paris Agreement. Drawing on analysis of 2098 Component Programme Activities in Clean Development Mechanism Pipeline by January 2017, they show that using qualitative data to label climate actions can be effective and much cheaper than a quantitative approach.

Each of INEAs issues over the last 20 years has highlighted design challenges in international environmental agreements; it has examined not only the politics, law and economics of the negotiations themselves, but also looked at the domestic translation and interpretation of these different agreements. What is also clear is that there is a vast literature on international environmental agreements, not only in our journal but in others journals. The next GEO-7 could possibly build on this literature to draw more closely on the lessons learnt from these journals and we could make sure that our lessons learnt are presented more comprehensively to future readers and users of INEA's insights.

Publisher's Note Springer Nature remains neutral with regard to jurisdictional claims in published maps and institutional affiliations. 